Cite this: Energy Environ. Sci., 2014, 7,

\title{
New insights into the electrochemical hydrogen oxidation and evolution reaction mechanism $\uparrow$
}

2255

Received 7th February 2014

Accepted 10th April 2014

DOI: $10.1039 / c 4 e e 00440 j$

www.rsc.org/ees

The effect of $\mathrm{pH}$ on the hydrogen oxidation and evolution reaction (HOR/HER) rates is addressed for the first time for the three most active monometallic surfaces: Pt, Ir, and Pd carbon-supported catalysts. Kinetic data were obtained for a proton exchange membrane fuel cell (PEMFC; $\mathrm{pH} \approx 0$ ) using the $\mathrm{H}_{2}$-pump mode and with a rotating disk electrode (RDE) in $0.1 \mathrm{M} \mathrm{NaOH}$. Our findings point toward: (i) a similar $\approx 100$-fold activity decrease on all these surfaces when going from low to high $\mathrm{pH}$; (ii) a reaction rate controlled by the Volmer step on $\mathrm{Pt} / \mathrm{C}$; and (iii) the $\mathrm{H}$-binding energy being the unique and sole descriptor for the HOR/HER in alkaline electrolytes. Based on a detailed discussion of our data, we propose a new mechanism for the HOR/HER on Pt-metals in alkaline electrolytes.

Fuel cells and electrolyzers are important for renewable energy conversion and storage. They are currently based on protonexchange membranes (PEMs) operating at low $\mathrm{pH}(\mathrm{pH} \approx 0)$, which offer high power densities, but require large amounts of platinum for the oxygen reduction reaction (ORR) in fuel cells ${ }^{1}$ and of Ir for the oxygen evolution reaction (OER) in electrolyzers. ${ }^{2}$ For the hydrogen oxidation/evolution reaction (HOR/HER) only very small amounts of Pt are required due to its extremely high activity for the HOR/HER. ${ }^{3}$ The $\mathrm{H}_{2}$ anode performance in PEMFCs suggested exchange current densities $\left(i^{0}\right)$ in the order of $10^{2} \mathrm{~mA} \mathrm{~cm}_{\mathrm{Pt}}{ }^{-2},{ }^{4}$ which was confirmed by mass-transport-free fuel cell measurements ${ }^{3,5}$ and microelectrode data. ${ }^{6}$ Until then, 100fold lower $i^{0}$-values for Pt in acid were reported erroneously, generally based on rotating disk electrode (RDE) measurements $^{7,8}$ from which, however, the kinetics of reactions with $i^{0}$-values much above the diffusion limited RDE current density $\left(\approx 2-3 \mathrm{~mA} \mathrm{~cm}_{\mathrm{disk}}{ }^{-2}\right.$ ) cannot be quantified. ${ }^{9}$

In an alkaline electrolyte, non-noble metal catalysts are very active for the $\mathrm{ORR}^{10,11}$ and for the OER, ${ }^{12,13}$ so that in

Technische Universität München, Lehrstuhl für Technische Elektrochemie, Lichtenbergstr. 4, 85748 Garching, Germany.E-mail:julien.durst@tum.de

$\dagger$ Electronic supplementary information (ESI) available: Materials, PEMFC and RDE measurement setups and extraction of exchange current densities from the polarization curves. See DOI: 10.1039/c4ee00440j

\begin{abstract}
Broader context
The future of electromobility relies on the development of cost effective and durable energy conversion systems such as fuel cells and electrolyzers. These devices, based on proton-exchange membranes (PEMs), operating at $\mathrm{pH} 0$, offer high power densities, but require large amounts of noble metal for the oxygen reduction reaction (ORR) in fuel cells and the oxygen evolution reaction (OER) in electrolyzers. For the hydrogen oxidation/evolution reaction (HOR/HER), only small amounts of Pt are required to activate this reaction, without contributing to any efficiency loss of the fuel cell or electrolyzer system. In alkaline electrolyte, nonnoble metal catalysts catalyze the ORR and OER at similar rates to Pt electrodes. Therefore, a replacement of the noble-metal PEM technology by alkaline membrane technology seems promising, and will offer new challenges in the field of electrocatalysis at high $\mathrm{pH}$. In particular, for as yet unclear reasons, the HOR/HER kinetics on Pt are much slower in alkaline than in acid electrolytes. It is therefore critical to elucidate the reasons for the poor HOR/HER activity of Pt in alkaline electrolytes, and this will certainly come only with a deeper fundamental understanding of this reaction and its mechanism, as we are presenting in this study.
\end{abstract}

conjunction with alkaline membranes $\left(\mathrm{OH}^{-}\right.$-exchange membranes ${ }^{\mathbf{1 4 , 1 5}}$ ) a replacement of the noble-metal intensive PEM technology by alkaline membrane technology seems promising. Unfortunately, for yet unclear reasons, the HOR/ HER kinetics on Pt are much slower in alkaline than in acid electrolytes, and large amounts of Pt are needed to catalyze the HOR/HER in an alkaline environment. ${ }^{9}$ Therefore, it is critical to develop alternative HOR/HER catalysts for alkaline electrolytes and - to guide this search - to elucidate the reasons for the poor HOR/HER activity of Pt in alkaline electrolytes.

Traditionally, the overall reactions have been written either with protons in acid or with hydroxide ions in alkaline media: ${ }^{\mathbf{1 6}}$ in acid:

$$
\mathrm{H}_{2} \leftrightarrows 2 \mathrm{H}^{+}+2 \mathrm{e}^{-}
$$

in base:

$$
\mathrm{H}_{2}+2 \mathrm{OH}^{-} \leftrightarrows 2 \mathrm{H}_{2} \mathrm{O}+2 \mathrm{e}^{-}
$$


In acid, reaction (1) is believed to be composed of two out of three microscopic steps (Tafel/Volmer or Heyrovsky/Volmer): ${ }^{\mathbf{1 6}}$

Tafel step:

$$
\mathrm{H}_{2} \leftrightarrows 2 \mathrm{H}_{\mathrm{ad}}
$$

Heyrovsky step:

$$
\mathrm{H}_{2} \leftrightarrows \mathrm{H}_{\mathrm{ad}}+\mathrm{e}^{-}+\mathrm{H}^{+}
$$

Volmer step:

$$
\mathrm{H}_{\mathrm{ad}} \leftrightarrows \mathrm{H}^{+}+\mathrm{e}^{-}
$$

In base, the Heyrovsky and the Volmer steps have conventionally been written with hydroxides rather than protons as reactants: ${ }^{17}$

Heyrovsky step:

$$
\mathrm{H}_{2}+\mathrm{OH}^{-} \leftrightarrows \mathrm{H}_{\mathrm{ad}}+\mathrm{e}^{-}+\mathrm{H}_{2} \mathrm{O}
$$

Volmer step:

$$
\mathrm{H}_{\mathrm{ad}}+\mathrm{OH}^{-} \leftrightarrows \mathrm{H}_{2} \mathrm{O}+\mathrm{e}^{-}
$$

The different proposed reactions in acid and base, where either $\mathrm{H}^{+}$(reactions (1), (4a), and (4b)) or $\mathrm{H}_{2} \mathrm{O} / \mathrm{OH}^{-}$(reactions (2), (5a), and (5b)) would be the reacting species, have recently been used to rationalize the $\approx 100$-fold larger $i^{0}$-value of Pt in acidic vs. alkaline electrolytes. ${ }^{18}$ Under this assumption, the authors proposed that a combination of Pt (known to be active for $\mathrm{H}_{2}$ dissociation, reaction (3)) with more oxophilic components (e.g., Ru or Ni) or the use of more oxophilic metals (e.g., Ir) would enhance the interaction with $\mathrm{H}_{2} \mathrm{O} / \mathrm{OH}^{-}$to yield higher HOR/HER activities in base. ${ }^{18}$

To further elucidate the HOR/HER activity differences in acid $v s$. base we will compare the $i^{0}$-values in both electrolytes of carbon supported platinum nanoparticles (Pt/C) with those of two other carbon supported metals: palladium (Pd/C) and the more oxophilic iridium (Ir/C). Particle sizes and specific surface areas of these catalysts are listed in Table 1. A rigorous comparison has not been performed before, since the HOR/ HER activity of $\mathrm{Pd} / \mathrm{C}$ and $\mathrm{Ir} / \mathrm{C}$ in acid might also be too high for reliable quantification by $\mathrm{RDE}$ experiments which has been used in the past. ${ }^{7,19,20}$ Here, we quantify for the first time the $i^{0}$ values of $\mathrm{Pd} / \mathrm{C}$ and $\mathrm{Ir} / \mathrm{C}$ nanoparticles using mass-transport free kinetic measurements in $\mathrm{a}_{2}$ pump configuration with proton exchange membrane based membrane electrode assemblies (MEAs). ${ }^{3}$

Table 1 Mean particle size $\left(\overline{d_{N}}\right)$ as well as TEM based and H-UPD based electrochemical active surface areas (ECSA $A_{T E M}$ and ECSA $A_{H-U P D}$, respectively) of $\mathrm{Pt} / \mathrm{C}, \mathrm{Ir} / \mathrm{C}$, and $\mathrm{Pd} / \mathrm{C}$ catalysts (see the $\mathrm{ESI}+$ )

\begin{tabular}{llllr}
\hline Sample & $\begin{array}{l}\text { Loading on C } \\
{[\mathrm{wt} \%]}\end{array}$ & $\begin{array}{l}\left(\overline{d_{\mathrm{N}}}\right) \\
{[\mathrm{nm}]}\end{array}$ & $\begin{array}{l}\mathrm{ECSA}_{\mathrm{TEM}} \\
{\left[\mathrm{m}^{2} \mathrm{~g}^{-1}\right]}\end{array}$ & $\begin{array}{l}\mathrm{ECSA}_{\mathrm{H}-\mathrm{UPD}} \\
{\left[\mathrm{m}^{2} \mathrm{~g}^{-1}\right]}\end{array}$ \\
\hline $\mathrm{Pt} / \mathrm{C}$ & 5 & $2.2 \pm 0.7$ & 110 & $120 \pm 20$ \\
$\mathrm{Ir} / \mathrm{C}$ & 20 & $3.3 \pm 0.9$ & 68 & $59 \pm 10$ \\
$\mathrm{Pd} / \mathrm{C}$ & 10 & $2.8 \pm 0.5$ & 173 & $105 \pm 20$
\end{tabular}
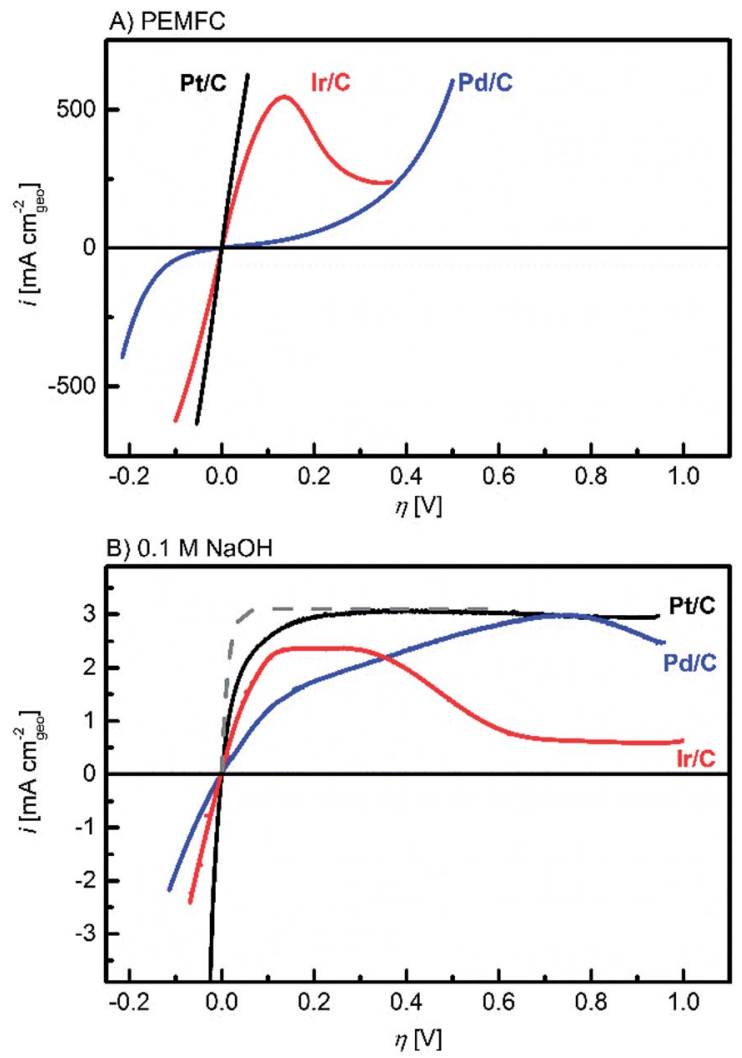

Fig. 1 Ohmic loss corrected polarization curves in a $\mathrm{H}_{2}$-saturated atmosphere at ambient pressure and $313 \mathrm{~K}$ on $\mathrm{Pt} / \mathrm{C}$ (black lines), Ir/C (red lines) and Pd/C (blue lines) in: (A) PEMFCs at $2 \mathrm{mV} \mathrm{s}^{-1}$ and (B) $0.1 \mathrm{M}$ $\mathrm{NaOH}$ at $10 \mathrm{mV} \mathrm{s}^{-1}$ (the negative going scans are shown) and 1600 rpm. In (B), the diffusion overpotential, calculated according to Sheng et al. ${ }^{9}$ is also shown (grey dashed line). For metal loadings see the ESI. $\dagger$

Fig. 1 displays iR-corrected HOR/HER polarization curves in units of $\mathrm{mA} \mathrm{cm}_{\text {geo }}{ }^{-2}$ for the Pt/C (black lines), Ir/C (red lines) and $\mathrm{Pd} / \mathrm{C}$ (blue lines) catalysts recorded in a PEMFC setup (Fig. 1A) ${ }^{3}$ and in a $0.1 \mathrm{M} \mathrm{NaOH}$ electrolyte (Fig. 1B). At both $\mathrm{pH}$ values, the high oxophilicity of the $\mathrm{Ir} / \mathrm{C}$ electrode is demonstrated by the decreasing HOR currents at $0.15-0.30 \mathrm{~V} v s$. RHE (reversible hydrogen electrode) due to the early formation of adsorbed $\mathrm{OH}_{\text {ads }}$ species. This oxophilic behaviour is similar to what was reported for $\mathrm{Ru}$ electrodes. ${ }^{21}$ For a quantitative comparison, the geometric current densities were normalized by the metal areas obtained by H-UPD (see the ESI $\dagger$ ) to yield specific current densities $\left(\mathrm{mA} \mathrm{cm}_{\text {metal }}{ }^{-2}\right.$ ), plotted in Fig. 2A (PEMFC) and $\mathrm{B}$ (0.1 M NaOH).

The polarization curves were fitted with a simple ButlerVolmer equation to get the $i^{0}$-values $\left(i_{313 \mathrm{~K}}^{0}\right.$, reported in Fig. $2 \mathrm{C}$ and Tables S1-S3†). ${ }^{22}$

$$
i=i_{313 \mathrm{~K}}^{0} \times\left(\mathrm{e}^{\frac{\alpha F \eta}{R T}}-\mathrm{e}^{\frac{-(1-\alpha) F \eta}{R T}}\right)
$$

where $\eta$ is the overpotential, $\alpha$ the transfer coefficient, $T$ the temperature, $R$ the gas constant $\left(8.314 \mathrm{~J} \mathrm{~mol}^{-1} \mathrm{~K}^{-1}\right)$ and $F$ the Faraday constant (96 $485 \mathrm{~A} \mathrm{~s} \mathrm{~mol}^{-1}$ ). Obviously, all metals are substantially less active in base. The reactivity follows the order 

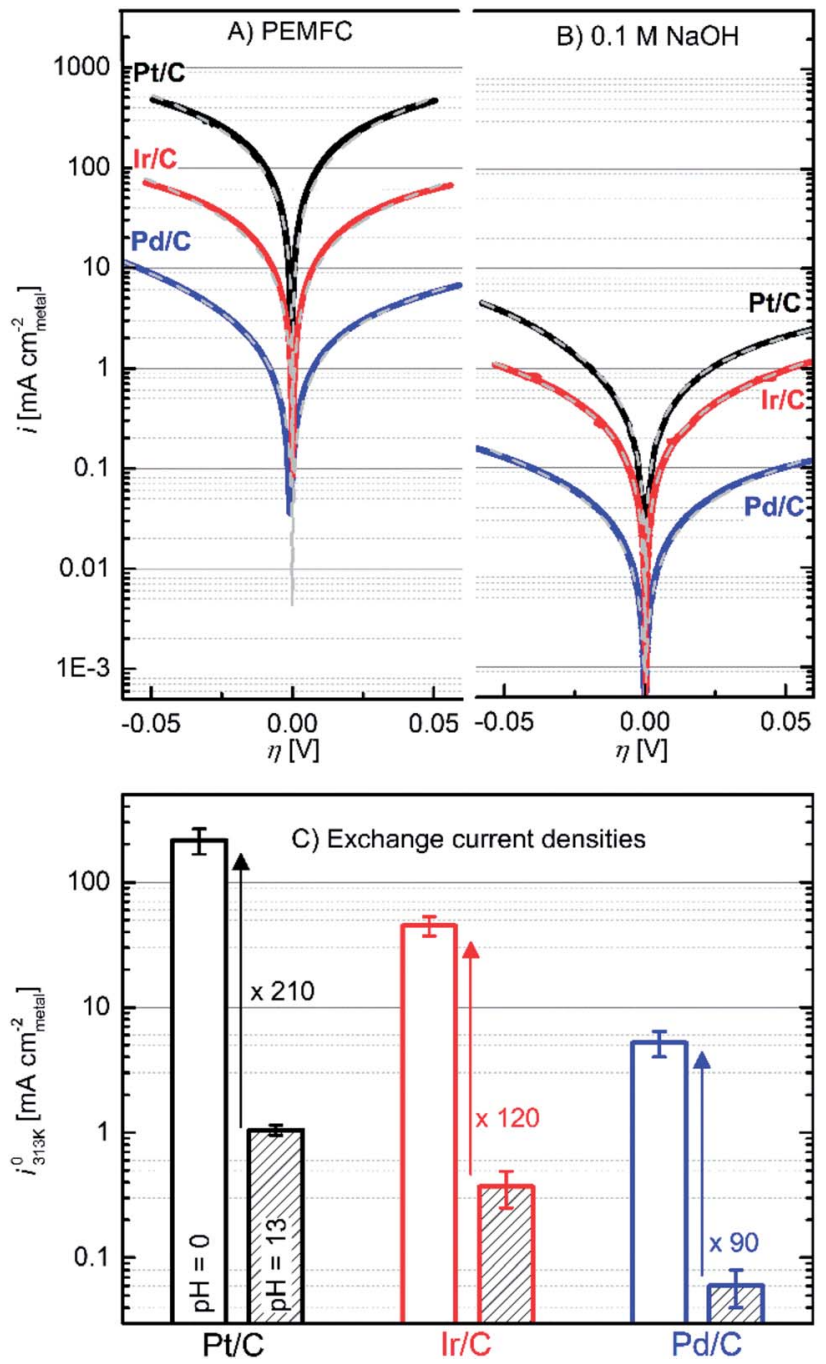

Fig. 2 Upper part: HOR/HER Tafel plots of the specific current densities on $\mathrm{Pt} / \mathrm{C}$ (black lines), Ir/C (red lines) and $\mathrm{Pd} / \mathrm{C}$ (blue lines) in: (A) PEMFC and (B) $0.1 \mathrm{M} \mathrm{NaOH}$ electrolyte. The Butler-Volmer fits are indicated as grey dashed lines. The extracted fitting parameters are reported in the ESI. $\dagger$ Lower part: HOR/HER exchange current densities $\left(i_{313 K}\right)$ in PEMFC (empty columns) and $0.1 \mathrm{M} \mathrm{NaOH}$ (striped columns) averaged from Butler-Volmer and micropolarization equations. Data recorded in a $\mathrm{H}_{2}$-saturated atmosphere at ambient pressure and $313 \mathrm{~K}$.

Pt $>$ Ir $>$ Pd in each electrolyte. The $i_{313 \mathrm{~K}}^{0}$ values, extracted from fitting eqn (6) to the data, agree well with those obtained from the micropolarization region $(-10$ to $+10 \mathrm{mV} v s$. RHE) described by the linearized form of the Butler-Volmer equation (see Tables S1-S3†):

$$
i^{0}=\frac{R T}{F} \frac{i}{\eta}=\frac{R T}{F} \frac{1}{R_{\mathrm{ct}}}
$$

where $R_{\mathrm{ct}}$ (in $\Omega \mathrm{cm}^{2}$ ) represents the charge transfer resistance. In acid, the $i_{313 \mathrm{~K}}^{0}$-values for $\mathrm{Pt} / \mathrm{C}$ are consistent with the literature $^{3}$ while the values for $\mathrm{Pd} / \mathrm{C}\left(0.2-0.8 \mathrm{~mA} \mathrm{~cm}_{\text {metal }}{ }^{-2}\right)^{7,20}$ and Ir/C $\left(0.2 \mathrm{~mA} \mathrm{~cm} \mathrm{~cm}_{\text {metal }}{ }^{-2}\right)^{7}$ were previously underestimated, presumably due to uncorrected mass transport effects. In alkaline electrolytes, the $i_{313 \mathrm{~K}}^{0}$-value agrees with the literature for Pt/C, ${ }^{9}$ but no values have been published for $\mathrm{Pd} / \mathrm{C}$ and $\mathrm{Ir} / \mathrm{C}$.
Owing to the large amount of data for platinum, we will first focus our discussion on Pt/C. Historically, the HOR/HER equilibrium has been described by invoking overpotential deposited hydrogen (H-OPD) as the adsorbed reaction intermediate species in the HOR/HER, which forms near and below the reversible $\mathrm{H}^{+} / \mathrm{H}_{2}$ potential. ${ }^{23}$ This was considered to be different in nature from the hydrogen species adsorbed on noble metal surfaces at potentials positive of the reversible $\mathrm{H}^{+} / \mathrm{H}_{2}$ potential, the so-called underpotential-deposited hydrogen (H-UPD). Thus, H-OPD was considered a reaction intermediate in the HOR/HER, while H-UPD was regarded as merely a spectator in the reaction. So far, no clear evidence of the difference in the physical nature of H-OPD and H-UPD species has ever been reported. On the other hand, in ab initio computational studies on the HOR/HER reaction, only a single type of adsorbed hydrogen intermediate species has been modeled, considering the three conceivable microscopic reactions, namely the Tafel, Volmer, and/or Heyrovsky reactions (usually in the form of reactions (1), (4a), and (4b)). ${ }^{24}$ However, no explicit difference has been demonstrated between the adsorbed hydrogen reaction intermediate and the H-UPD. In what follows, we will show for the first time that the HOR/HER and the H-UPD reaction, formally the same as the Volmer reaction (reaction (4b)), have identical rates, so that no H-OPD species have to be invoked to describe the HOR/HER rates.

To support this hypothesis, we will compare the charge transfer resistance for the H-UPD reaction with the exchange current density of the HOR/HER reaction. The reported H-UPD charge transfer resistances from AC impedance studies in aqueous $\mathrm{HClO}_{4}$ are $\approx 0.03 \Omega \mathrm{cm}^{2}$ for $\operatorname{Pt}(111)^{25}$ and $\approx 0.05 \Omega \mathrm{cm}^{2}$ for polycrystalline $\mathrm{Pt} ;{ }^{26}$ using eqn (7), these equate to $i^{0}$-values for the Volmer reaction of $\approx 850 \mathrm{~mA} \mathrm{~cm}_{\mathrm{Pt}}{ }^{-2}$ and $\approx 500 \mathrm{~mA}$ $\mathrm{cm}_{\mathrm{Pt}}{ }^{-2}$, respectively. These are indeed very similar to the HOR/ HOR exchange current density of $i_{313 \mathrm{~K}}^{0} \approx 200 \mathrm{~mA} \mathrm{~cm}_{\mathrm{Pt}}{ }^{-2}$ on Pt/ $\mathrm{C}$ obtained from our kinetic measurements (Fig. 2C and Table $\mathrm{S} 1 \dagger)$. Note that an accurate determination of the H-UPD kinetics in an acid electrolyte by impedance spectroscopy is very delicate ${ }^{25}$ and will also depend on the platinum catalyst morphology (particle size, crystal face), so that a rigorous quantitative comparison can only be made when the HOR/HER exchange current density and the H-UPD charge transfer resistance are measured for the same catalyst (this will be reported in future communications ${ }^{27}$ ). To complete the analysis in an acidic electrolyte, Vogel et al. showed by means of gas phase hydrogen-deuterium measurements that the Tafel step (reaction (3)) could be the rate determining step (rds) followed by a fast Volmer step (reaction (4b)). ${ }^{28}$ If this were true, the Butler-Volmer relationship derived in the case of a rate limiting Tafel step ${ }^{\mathbf{1 6}}$ would result in HOR and HER Tafel slopes of $\approx 30 \mathrm{mV}$ per decade (i.e., $\alpha=2$ ) while our mass transport free PEMFC data show 4 times higher Tafel slopes $(\alpha=0.5$, see the ESI $\dagger$ ), in agreement with a Butler-Volmer relationship derived for a Volmer or a Heyrovsky rate limiting step. Thus, the possibility of a Tafel rate determining step can be clearly discarded.

In $0.05 \mathrm{M} \mathrm{NaOH}$, the charge transfer resistance of 13-54 $\Omega \mathrm{cm}^{-2}$ obtained on (stepped) single crystal Pt surfaces equates 
to $0.2-0.5 \mathrm{~mA} \mathrm{~cm}{ }_{\mathrm{Pt}}{ }^{-2},{ }^{17}$ which is very close to our value of 1.0 $\mathrm{mA} \mathrm{cm}_{\mathrm{Pt}}{ }^{-2}$, obtained for $\mathrm{Pt} / \mathrm{C}$ in $0.1 \mathrm{M} \mathrm{NaOH}$ (Fig. 2C). This again suggests that the HOR/HER kinetics on $\mathrm{Pt}$ in an alkaline electrolyte are limited by the Volmer step (reactions $(4 b) /(5 b)$ ).

One possibility for the reduced rate of the Volmer step in base would be a higher $\mathrm{H}-\mathrm{Pt}$ bond strength, which would slow down both the HOR and the HER rates. A higher $\mathrm{H}-\mathrm{Pt}$ bond strength is further confirmed by the above discussed charge transfer resistance values for the H-UPD reaction, but also by the reported positive-shift of the H-UPD peaks with increasing pH. These shifts on $\operatorname{Pt}(553)$ and $\operatorname{Pt}(533)^{29}$ as well as on polycrystalline $\mathrm{Pt}^{30}$ amount to $\approx 10 \mathrm{mV}_{\mathrm{RHE}} \mathrm{pH}^{-1}$ and $\approx 11 \mathrm{mV}_{\mathrm{RHE}} \mathrm{pH}^{-1}$, respectively. Qualitatively, the same is observed in Fig. 3A for $\mathrm{Pt} / \mathrm{C}$, but the H-UPD peaks on Pt/C are too broad to get a sufficiently precise value. Using the values for smooth crystals, the H-UPD peak shift $\left(\Delta E_{\mathrm{H} \text {-UPD }}\right)$ would translate into a $\mathrm{H}$-binding energy difference of $\Delta E_{\text {binding }} \approx 12.5-13.5 \mathrm{~kJ} \mathrm{~mol}^{-1}$ from $\mathrm{pH}=0$ to $\mathrm{pH}=13$ (from $\Delta E_{\mathrm{H} \text {-UPD }} \times F$ for a 1-electron process). If we assume that the difference in the $\mathrm{H}$-binding energy is proportional to the difference in the activation energy (as described by the Brønsted-Evans-Polany relationship ${ }^{31}$ ), then the difference
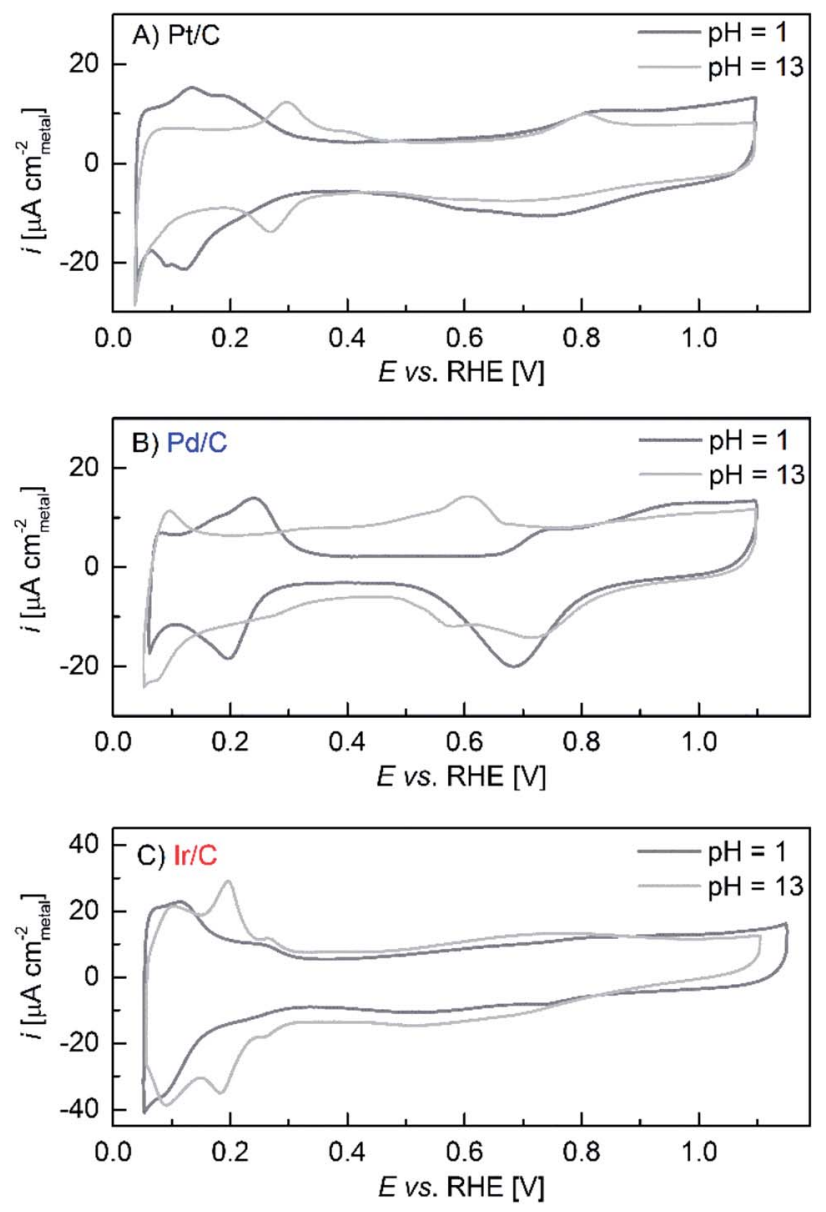

Fig. 3 Voltammograms at $293 \mathrm{~K}$ recorded in an Ar-saturated atmosphere at $20 \mathrm{mV} \mathrm{s}^{-1}$ in $0.1 \mathrm{M} \mathrm{NaOH}$ (light grey line) and $0.1 \mathrm{M} \mathrm{HClO}_{4}$ (dark grey line), except for $\mathrm{Ir} / \mathrm{C}$ which was recorded in $0.05 \mathrm{M} \mathrm{H}_{2} \mathrm{SO}_{4}$ since Ir reacts with $\mathrm{ClO}_{4}{ }^{-}$ions (see Reier et al. ${ }^{2}$ and ref. 39-41 therein). in the $\mathrm{HOR} / \mathrm{HER}$ rate between $\mathrm{pH}=0$ and $\mathrm{pH}=13$ for $\mathrm{Pt}$ could be predicted by the Arrhenius equation

$$
r_{\mathrm{pH}=0} / r_{\mathrm{pH}=13} \approx \exp \left[\Delta E_{\text {binding }} / R T\right]
$$

and would amount to a factor of 120-200. This is actually surprisingly close to the 210 -fold difference in $i_{313 \mathrm{~K}}^{0}$ (Fig. 2C), giving further credence to the hypothesis that the Volmer step is the rate limiting step for the HOR/HER on Pt.

Fundamental studies of the HOR/HER on bulk Pd crystals are complicated by the fact that the H-UPD process (adsorption) is difficult to separate from $\mathrm{H}$-absorption. ${ }^{32}$ Therefore, studies have mostly been focused on Pd monolayers (ML) deposited on Au substrates. ${ }^{33-35}$ While 5 ML-Pd/Au(111) surfaces also show a large increase in the H-UPD charge transfer resistance between acid $^{36}$ and base, ${ }^{37}$ namely from $\approx 500 \Omega \mathrm{cm}^{2}\left(\equiv 0.05 \mathrm{~mA} \mathrm{~cm}_{\mathrm{Pd}}{ }^{-2}\right)$ in $0.1 \mathrm{M} \mathrm{HClO}_{4}$ to $\approx 8000 \Omega \mathrm{cm}^{2}\left(\equiv 0.003 \mathrm{~mA} \mathrm{~cm}_{\mathrm{Pd}}{ }^{-2}\right)$ in $0.1 \mathrm{M}$ $\mathrm{NaOH}$, there is no quantitative agreement with the $i^{0}$-values shown in Fig. 2C, as was the case for Pt. This may be related to residual $\mathrm{H}$-absorption effects and, as was mentioned by the authors, contamination effects in their $\mathrm{NaOH}$ electrolyte. ${ }^{37}$ Overall, however, these measurements rationalize the hereobserved decrease in HOR/HER activity with increasing $\mathrm{pH}$ (Fig. 2C) and also point towards the Volmer step as rate limiting.

Iridium being the most oxophilic of the three surfaces (Fig. 1) is an interesting case, as it probes the hypothesis advanced by Strmcnik et al. that a more oxophilic surface might be effective in catalyzing the interaction with $\mathrm{H}_{2} \mathrm{O} / \mathrm{OH}^{-}$in reaction (2) which they proposed to be the governing reaction in base. ${ }^{18}$ However, our findings demonstrate explicitly that Ir does not have a higher activity than Pt in base (nor in acid), which is in disagreement with Strmcnik et al. ${ }^{18}$ and would lead to the conclusion that $\mathrm{OH}^{-}$adsorption or $\mathrm{H}_{2} \mathrm{O}$ dissociation is not the rate determining step in base. The reason for this discrepancy might be that all polarization curves reported in Fig. 1 were recorded after a stable state of the surface was reached (after a few cyclic voltammograms), while Strmcnik et al. only showed the very first anodic scan. ${ }^{\mathbf{1 8}}$ These authors also provided HOR/ HER first-scan data on $\mathrm{Pt}_{0.5} \mathrm{Ru}_{0.5}$ and $\mathrm{Pt}_{0.1} \mathrm{Ru}_{0.9}$ bulk crystals, whereby the latter showed the highest activity, supporting their argument that more oxophilic surfaces would promote the HOR/HER kinetics. While Strmcnik et al. considered the strong $\mathrm{Pt}$ surface enrichment on their vacuum-annealed $\mathrm{Pt}-\mathrm{Ru}$ alloys, ${ }^{38}$ they erroneously quoted from ref. 38 that the surface composition of $\mathrm{Pt}_{0.5} \mathrm{Ru}_{0.5}$ and $\mathrm{Pt}_{0.1} \mathrm{Ru}_{0.9}$ would be 90 at.\% and 50 at.\% $\mathrm{Pt}$, respectively, while the correct values are 85 at.\% and 90 at.\% $\mathrm{Pt}$, respectively (the reasons are discussed in ref. 38). Thus, the most active surface was the one with the lowest $\mathrm{Ru}$ surface composition (annealed $\mathrm{Pt}_{0.1} \mathrm{Ru}_{0.9}$ ), i.e., the less oxophilic. Another argument in support of their hypothesis that the HOR/ HER in base requires the interaction with $\mathrm{H}_{2} \mathrm{O} / \mathrm{OH}^{-}$as suggested by reactions (2) and (5b) was based on their kinetic model to describe the $\mathrm{pH}$ dependence of the HOR/HER on Pt in unbuffered electrolytes between $\mathrm{pH}=2.5$ and $\mathrm{pH}=10.5$. From this they deduced that the reaction mechanism would change when going from acid (reaction (1)) to base (reaction (2)). This conclusion, however, is invalid since recent calculations and 
experiments by Auinger et al. clearly showed that the observed response in unbuffered solutions is merely due to local $\mathrm{pH}$ gradients and does not reflect any changes of the HOR/HER kinetics. ${ }^{39}$

So far we conclude that there is no substantiated evidence that the HOR/HER reactions in base proceed according to reactions (2) and (5b). In our opinion, reaction (2) merely represents an algebraic exercise, i.e., adding $2 \mathrm{OH}^{-}$to both sides of reaction (1) (the same is true for the Volmer steps, reactions (4b) and (5b)). Considering that the bulk of aqueous solutions of $0.1 \mathrm{M}$ base and $0.1 \mathrm{M}$ acid contains molecular ratios of $\mathrm{H}_{2} \mathrm{O} / \mathrm{OH}^{-}$and $\mathrm{H}_{2} \mathrm{O} / \mathrm{H}^{+}$of 550/1 (grantedly, this ratio might be somewhat lower at the metal/solution interface) and that $\mathrm{H}_{2} \mathrm{O}$ is a very fast $\mathrm{H}^{+}$donor/acceptor, we believe that the microscopic reactions for the HOR/HER are represented by reactions (3) and (4b) (or, alternatively, reactions (4a) and (4b)). While the overall reaction (2) will still hold true, it is, however, more likely composed of coupled surface and bulk reactions:

$\Sigma$ (surface reactions):

$$
\mathrm{H}_{2} \leftrightarrows 2 \mathrm{H}^{+}+2 \mathrm{e}^{-}
$$

$\mathrm{H}_{2} \mathrm{O}$ dissociation:

$$
2 \mathrm{H}^{+}+2 \mathrm{OH}^{-} \leftrightarrows 2 \mathrm{H}_{2} \mathrm{O}
$$

The sum of reactions (9) and (10), of course, will yield the overall reaction (2). Since $\mathrm{H}_{2} \mathrm{O}$ is a fast $\mathrm{H}^{+}$-donor/acceptor and since it is the major species in the solution (and at the metal/ solution interface), we believe that the microscopic Heyrovsky (reaction (4a)) and Volmer (reaction (4b)) steps do not change with $\mathrm{pH}$. This would be consistent with the observation that the HOR/HER kinetics between acid and base change by a very similar factor for the three studied Pt metals and that the H-binding energy (affected for each metal by the alkalinity of the environment, as can be deduced from the H-UPD shifts shown in Fig. 3) seems to be a good descriptor for the HOR/HER both in acid and base. ${ }^{40}$ While we cannot definitively prove this hypothesis, it is certainly the simplest mechanism which is consistent with the data.

\section{Conclusions}

In conclusion, we have shown that the HOR/HER activity at high $\mathrm{pH}$ follows the order $\mathrm{Pt}>\mathrm{Ir}>\mathrm{Pd}$, with exchange current densities which are much larger than those measured ${ }^{7}$ and calculated $^{24}$ previously. We have also shown for the first time that the exchange current densities on carbon-supported Pt, Pd and Ir electrodes are all decreased by about two orders of magnitude when moving from low $(\mathrm{pH}=0)$ to high $\mathrm{pH}(\mathrm{pH}=$ 13). This result is a clear proof that the oxophilicity of a catalyst (Ir being more oxophilic than Pt and Pd) does not enhance the HOR/HER activities in high $\mathrm{pH}$. From a mechanistic point of view, by comparing our measured HOR/HER kinetics with published H-UPD charge transfer resistance values, we have provided substantial evidence that the Volmer step is the rate determining step on noble metal electrodes and that therefore no H-OPD species have to be invoked to describe the HOR/HER rates. Furthermore, our analysis suggests that the H-UPD reaction is identical to the Volmer reaction, in support of the hypothesis raised by Chen and Kucernak. ${ }^{6}$ Addressing now the pH effect, our results point toward identical microscopic HOR/ HER reaction steps in acid and base and that the H-binding energy is the relevant descriptor in both electrolytes, even though the origin of the difference in H-binding energy is not clear at this point. None of the current DFT models considers any effect of $\mathrm{pH}$ on the $\mathrm{H}$-binding energy. ${ }^{\mathbf{2 4 , 4 0 , 4 1}}$ In a recent study, Rossmeisl et al. initiated an attempt to address $\mathrm{pH}$ in DFT calculation in order to examine its effect on adsorbate coverage and configuration at the $\mathrm{Pt}(111) /$ electrolyte interface ${ }^{\mathbf{4 2}}$ and proposed that the local water configuration might be different in acid $v s$. base, thus affecting the HOR/HER kinetics; however, its effect on the H-binding energy was not determined even though our data suggest that this might be the origin of the large observed differences.

Based on the above analysis, the design of new and advanced electrocatalysts for the hydrogen oxidation and evolution reaction in alkaline fuel cells and electrolyzers would benefit from: (i) improved computational calculations/models which include the $\mathrm{pH}$ effect on the H-binding energy, (ii) the development of experimental methods which allow quantification of the $\mathrm{H}$ binding energy, and (iii) the synthesis of electrocatalysts with tuned H-binding energies.

\section{Acknowledgements}

The authors would like to thank Dr Marianne Hanzlik for TEM measurements, and Tanaka Kikinzoku Kogyo and Premetek for the supply of the catalysts.

\section{Notes and references}

1 H. A. Gasteiger and N. M. Markovic, Science, 2009, 324, 4849.

2 T. Reier, M. Oezaslan and P. Strasser, ACS Catal., 2012, 2, 1765-1772.

3 K. C. Neyerlin, W. Gu, J. Jorne and H. A. Gasteiger, J. Electrochem. Soc., 2007, 154, B631-B635.

4 H. A. Gasteiger, J. E. Panels and S. G. Yan, J. Power Sources, 2004, 127, 162-171.

5 X. Wang, R. Ahluwalia and A. Steinbach, J. Electrochem. Soc., 2013, 160, F251-F261.

6 S. Chen and A. Kucernak, J. Phys. Chem. B, 2004, 108, 1398413994.

7 S. Trasatti, J. Electroanal. Chem., 1972, 39, 163-184.

8 N. Markovic, B. Grgur and P. Ross, J. Phys. Chem. B, 1997, 101, 5405-5413.

9 W. Sheng, H. A. Gasteiger and Y. Shao-Horn, J. Electrochem. Soc., 2010, 157, B1529-B1536.

10 J. Suntivich, H. A. Gasteiger, N. Yabuuchi and Y. Shao-Horn, J. Electrochem. Soc., 2010, 157, B1263-B1268.

11 T. Poux, F. Napolskiy, T. Dintzer, G. Kéranguéven, S. Y. Istomin, G. Tsirlina, E. Antipov and E. Savinova, Catal. Today, 2012, 189, 83-92. 
12 C. C. McCrory, S. Jung, J. C. Peters and T. F. Jaramillo, J. Am. Chem. Soc., 2013, 135, 16977-16987.

13 J. Suntivich, K. J. May, H. A. Gasteiger, J. B. Goodenough and Y. Shao-Horn, Science, 2011, 334, 1383-1385.

14 G. Merle, M. Wessling and K. Nijmeijer, J. Membr. Sci., 2011, 377, 1-35.

15 C. G. Arges, V. Ramani and P. N. Pintauro, Electrochem. Soc. Interface, 2010, 31.

16 K. Krischer and E. R. Savinova, in Handbook of Heterogeneous Catalysis, ed. G. Ertl, H. Knözinger, F. Schüth and J. Weitkamp, Wiley-VCH, Chichhester, 2009, pp. 1873-1905.

17 K. Schouten, M. van der Niet and M. Koper, Phys. Chem. Chem. Phys., 2010, 12, 15217-15224.

18 D. Strmcnik, M. Uchimura, C. Wang, R. Subbaraman, N. Danilovic, D. Van der Vilet, A. P. Paulikas, V. Stamenkovic and N. Markovic, Nat. Chem., 2013, 5, 300306.

19 M. Shao, J. Power Sources, 2011, 196, 2433-2444.

20 S. N. Pronkin, A. Bonnefont, P. S. Ruvinskiy and E. R. Savinova, Electrochim. Acta, 2010, 55, 3312-3323.

21 H. A. Gasteiger, N. M. Markovic and P. N. Ross Jr, J. Phys. Chem., 1995, 99, 16757-16767.

22 J. S. Newman, Electrochemical Systems, Prentice Hall, New York, 1991.

23 B. Conway and B. Tilak, Electrochim. Acta, 2002, 47, 35713594.

24 E. Skúlason, V. Tripkovic, M. E. Björketun, S. Gudmundsdottir, G. Karlberg, J. Rossmeisl, T. Bligaard, H. Jónsson and J. K. Nørskov, J. Phys. Chem. C, 2010, 114, 18182-18197.

25 E. Sibert, R. Faure and R. Durand, J. Electroanal. Chem., 2001, 515, 71-81.

26 B. Łosiewicz, R. Jurczakowski and A. Lasia, Electrochim. Acta, 2012, 80, 292-301.

27 P. J. Rheinländer, J. Durst, J. Herranz and H. A. Gasteiger, in preparation.
28 W. Vogel, L. Lundquist, P. Ross and P. Stonehart, Electrochim. Acta, 1975, 20, 79-93.

29 M. J. van der Niet, N. Garcia-Araez, J. Hernández, J. M. Feliu and M. Koper, Catal. Today, 2013, 202, 105-113.

30 R. Gisbert, G. García and M. Koper, Electrochim. Acta, 2010, 55, 7961-7968.

31 J. K. Nørskov, T. Bligaard, A. Logadottir, S. Bahn, L. B. Hansen, M. Bollinger, H. Bengaard, B. Hammer, Z. Sljivancanin and M. Mavrikakis, J. Catal., 2002, 209, 275-278.

32 M. Baldauf and D. Kolb, Electrochim. Acta, 1993, 38, 21452153.

33 L. A. Kibler, A. M. El-Aziz, R. Hoyer and D. M. Kolb, Angew. Chem., Int. Ed., 2005, 44, 2080-2084.

34 C. Gabrielli, P. Grand, A. Lasia and H. Perrot, J. Electrochem. Soc., 2004, 151, A1925-A1936.

35 C. Gabrielli, P. Grand, A. Lasia and H. Perrot, J. Electrochem. Soc., 2004, 151, A1937-A1942.

36 H. Duncan and A. Lasia, Electrochim. Acta, 2007, 52, 6195-6205.

37 M. Martin and A. Lasia, Electrochim. Acta, 2009, 54, 52925299.

38 H. Gasteiger, P. N. Ross Jr and E. Cairns, Surf. Sci., 1993, 293, 67-80.

39 M. Auinger, I. Katsounaros, J. C. Meier, S. O. Klemm, P. U. Biedermann, A. A. Topalov, M. Rohwerder and K. J. J. Mayrhofer, Phys. Chem. Chem. Phys., 2011, 13, 16384-16394.

40 W. Sheng, M. Myint, J. G. Chen and Y. Yan, Energy Environ. Sci., 2013, 6, 1509-1512.

41 J. K. Nørskov, T. Bligaard, A. Logadottir, J. Kitchin, J. Chen, S. Pandelov and U. Stimming, J. Electrochem. Soc., 2005, 152, J23-J26.

42 J. Rossmeisl, K. Chan, R. Ahmed, V. Tripkovic and M. Bjorketun, Phys. Chem. Chem. Phys., 2013, 15, 1032110325. 